\title{
Changing Narratives and Persisting Tensions: Conflicts between Chinese and Western Medicine and Professional Profiles in Chinese Films and Literature, 1949-2009
}

\author{
XIAOPING FANG * \\ School of Humanities, Nanyang Technological University, \\ 48 Nanyang Avenue, Singapore 639818, Singapore
}

\begin{abstract}
This paper analyses the shifting images of Chinese medicine and rural doctors in the narratives of literature and film from 1949 to 2009 in order to explore the persisting tensions within rural medicine and health issues in China. Popular anxiety about health services and the government's concern that it be seen to be meeting the medical needs of China's most vulnerable citizens - its rural dwellers - has led to the production of a continuous body of literary and film works discussing these issues, such as Medical Practice Incident, Spring Comes to the Withered Tree, Chunmiao, and Barefoot Doctor Wan Quanhe. The article moves chronologically from the early years of the Chinese Communist Party's new rural health strategies through to the twenty-first century - over these decades, both health politics and arts policy underwent dramatic transformations. It argues that despite the huge political investment on the part of the Chinese Communist Party government in promoting the virtues of Chinese medicine and barefoot doctors, film and literature narratives reveal that this rustic nationalistic vision was a problematic ideological message. The article shows that two main tensions persisted prior to and during the Cultural Revolution, the economic reform era of the 1980s, and the medical marketisation era that began in the late 1990s. First, the tension between Chinese and Western medicine and, second, the tension between formally trained medical practitioners and paraprofessional practitioners like barefoot doctors. Each carried shifting ideological valences during the decades explored, and these shifts complicated their portrayal and shaped their specific styles in the creative works discussed. These reflected the main dilemmas around the solutions to rural medicine and health care, namely the integration of Chinese and Western medicines and blurring of boundaries between the work of medical paraprofessionals and professionals.
\end{abstract}

Keywords: China, Health, Rural doctors, Barefoot doctors, Chinese medicine, Literary narratives

\footnotetext{
* Email address for correspondence: xpfang@ntu.edu.sg
} 


\section{Introduction}

Studies of rural medicine and health in post-1949 China have gone through three major thematic shifts, and have moved from looking at health politics, to medical practice, and then to visual presentation, with a particular focus on barefoot doctors during the 1960s and 1970s. The study of health politics in the Mao era first argued that, as medical paraprofessionals, barefoot doctors reflected the political ideologies and rural development strategies of the Cultural Revolution (1966-76). Barefoot doctors gained political recognition and acclaim from both the Chinese government and the international community as 'a low-cost solution built around easily available indigenous medicine in the 1970s' ${ }^{1}$ More recent studies of the social history of medicine, health and epidemic prevention in rural China point out that what barefoot doctors actually did was to introduce modern Western medicine to rural China, effectively modernising existing methods and establishing forms of care known as 'revolutionary Maoist medicine'. Barefoot doctors formed a group identity and then started a medical profession from scratch in rural communities. $^{2}$ In the meantime, research into visual presentations of barefoot doctors during the Cultural Revolution shows that films and posters served to represent class struggles among medical practitioners and the integration of Chinese and Western medicines, while showing how the combination of the 'opposing elements of self-cultivation and self-annihilation unite the identity of an emerging group of amateur doctors'. 3

Across the spectrum of political propaganda, medical practice and the visual arts, these studies define, portray and interpret two dynamic tensions - Chinese medicine vs. Western medicine, and paraprofessionals vs. professionally trained doctors. These tensions persisted during the process of implementing medical and health policies in rural China from 1949 onward, becoming sources of inspiration for literature and films concerning health and medicine from the 1950s onward. These tensions have been transformed into complicated, nuanced narratives that reflect the shifting political and medical ideologies that have underpinned the policies and practice of rural medicine and health, and affected appraisals of health policies implemented during previous political stages.

This article moves chronologically through representative works of Chinese films and literature concerning medicine and health that were published or released during major medical and health campaigns. These include the creation of union clinics in the 1950s, the mass epidemic prevention movements in the late 1950s and early 1960s, the barefoot doctor programme in the $1970 \mathrm{~s}$, and medical marketisation since the early $1980 \mathrm{~s}^{4}{ }^{4}$ It investigates how political and medical ideologies shaped narrative styles concerning the tensions between Chinese and Western medicine, and between paraprofessionals such as

\footnotetext{
${ }^{1}$ World Bank, China: Long-Term Issues and Options in the Health Transition (Washington, DC: The World Bank, 1992), 18; David Lampton, The Politics of Medicine in China: The Policy Process, 1949-77 (Boulder, CO: Westview Press, 1977); Victor W. Sidel, 'The Barefoot Doctors of the People's Republic of China', New England Journal of Medicine 286 (1972), 1292-300.

2 Gross Miriam, 'Between Party, People, and Profession: The Many Faces of the "Doctor" during the Cultural Revolution', Medical History, 62, 3 (2018), 333-59; Xiaoping Fang, Barefoot Doctors and Western Medicine in China (Rochester, NY: University of Rochester Press, 2012).

${ }^{3}$ Lan Angela Li, 'The Edge of Expertise: Representing Barefoot Doctors in Cultural Revolution China', Endeavour, 39, 304 (2015), 160-7.

${ }^{4}$ For literary works on maternal and child health and reproduction in rural China, see Ruo Zhijuan, 'Jingjing de chanyuan' [Quiet Obstetrics Hospital], in Ruo zhijuan xiaoshuoxuan [A Selection of Ruo Zhijuan's Fictions] (Chengdu: Sichuan renmin chubanshe, 1983); Mo Yan, Wa [Frog] (Shanghai: Shanghai wenyi chubanshe, 2012).
} 
barefoot doctors and professionally trained medical practitioners. The central thesis of the article examines how the definitions, portrayals and interpretations of tensions in these shifting narratives reflected a dilemma around two possible solutions to rural medicine and healthcare; namely, the integration of Chinese and Western medicines and the blurring of the boundaries between medical paraprofessionals and professionals. In this way, the article provides new illustrations for a story whose plot is familiar from standard written sources and therefore constitutes a rich archive for the study of Chinese medicine and rural doctors in China.

\section{Contesting Chinese and Western Medicine: Legitimacy and Efficacy}

After the establishment of the People's Republic of China in 1949, the legitimacy of Chinese medicine was interpreted from political, scientific and practical perspectives. The organisation of union clinics by Chinese medical practitioners and folk healers and the 'unification of Chinese and Western medicine' were proposed and adopted by the Communist government in 1950 to address the scarcity of medical personnel and resources, thus granting Chinese medicine political legitimacy. ${ }^{5}$ Ironically, the scientific legitimacy of Chinese medicine had been seriously challenged by Western medicine, which described it as 'feudal medicine', and there were policy restrictions around practising it until Mao himself called for the 'integration of Chinese and Western medicine' in $1956 .{ }^{6}$ However, even before this, Chinese medicine still enjoyed practical legitimacy as it was the main available resource in vast areas of rural China that Western medicine had yet to reach on a large scale. ${ }^{7}$ This changing legitimacy of Chinese medicine became a source of inspiration for works of Chinese literature and film that touched on the relationship between Chinese and Western medicine in union clinics that were overseen by the new Communist government. In these literary works, Western medical practitioners were intentionally set in new medical spaces, the arrival of which gave rise to a legitimacy crisis around the discipline of Chinese medicine. The works portray practitioners of Western medicine aggressively criticising Chinese medicine as being unscientific and backward. These accusations encounter fierce responses from Chinese medical practitioners, who argue for the practical efficacy of their approach.

These tensions between Chinese and Western medicine are at the heart of Li Zhun's short story 'Mr Li Si', published in 1957. In the novel, a Communist cadre from the township criticises $\mathrm{Mr} \mathrm{Li}$, the eponymous Chinese medicine doctor, by arguing that 'gold, wood, water, fire, and earth' were feudal notions. However, $\mathrm{Mr} \mathrm{Li}$ interprets these elements as 'heart, liver, spleen, and lung'. In Chinese medicine, Shanghan (febrile diseases or typhoid) are conceived differently than in Western medicine. In the story, Mr Li's defence of the theoretical legitimacy of Chinese medicine seems to be supported by the practical efficacy of his treatments, such as prescribing his patients two doses of simple but effective medicine. $^{8}$

\footnotetext{
${ }^{5}$ Miriam Gross, Farewell to the God of Plague: Chairman Mao's Campaign to Deworm China (Berkeley, CA: University of California Press, 2016), 28; Xiaoping Fang, 'From Union Clinics to Barefoot Doctors: Village Healers, Medical Pluralism, and State Medicine in Chinese Villages', Journal of Modern Chinese History, 2, 2 (2008), 223-41.

${ }^{6}$ Bridie Andrews, The Making of Modern Chinese Medicine, 1850-1960 (Vancouver: University of British Columbia Press, 2014), 208-9; Volker Scheid, Chinese Medicine in Contemporary China: Plurality and Synthesis (Durham, NC: Duke University Press, 2002), 65-88.

${ }^{7}$ Fang, op. cit. (note 2), 45-7.

${ }^{8}$ Li Zhun, 'Lisi xiansheng' [Mr Li Si], Renmin wenxue [People's literature], 3 (1957), 99-100.
} 
Another Chinese medical practitioner is more radically challenged by Western medicine in the short story 'Medical Practice Incident', by Xi Rong, also published in 1957. It centres on, Mr Niu, a hereditary folk healer who specialises in treating children's illnesses. Mr Niu is known as 'Mr Folk Recipe Niu' by villagers for his simple but effective recipes and diagnostic methods. As Xi Rong describes, 'the medicines that he prescribes are something like Chinese plantain, black sesame, and white pepper, which are readily available and don't need to be purchased from pharmacy. They not only save money but also cure illness.' However, he is excluded from the newly established health clinic dominated by young Western medicine doctors in 1956 on the grounds of his alleged illiteracy, ignorance of pathology and unscientific and backward methods. He is even stripped of his medical licence by the county health bureau. Niu defends himself by invoking the hereditary family tradition that reaches back to before his great-grandfather's times, and the practical efficacy of his treatments, which none of his patients had ever criticised as being backward and unscientific. ${ }^{9}$

In both these short stories, the aggressively pro-Western medicine campaign is promoted by arrogant and bureaucratic Communist Party officials, as Western medicine was a sign of political correctness and scientific legitimacy. As the director warns villagers in 'Medical Practice Incident', 'opposing Western medicine means opposing the people's government'. ${ }^{10}$ Both were published during the Hundred Flowers Campaign that had been underway since 1956. Criticism of past policies and practices was a key theme of literary works at this time, in response to Mao's guiding principle, 'Let a hundred flowers blossom and a hundred schools of thought contend'. In this context, government support for the aggressiveness of Western medicine was interpreted politically as an example of bureaucracy. Official attacks against Chinese medicine and the delegitimisation of it thus become objects of criticism in fictional works such as these two short stories.

In contrast, Western medicine itself is not criticised. What is proposed and encouraged is an equal status for Chinese and Western medicine and further integration of the two. 'Mr Li Si', reaches a happy ending in this sense after some initial resistance and confrontation; $\mathrm{Mr}$ Li Si becomes the director of the newly established union clinic and works alongside a young Western medicine doctor. Even the physical structure of the clinic comes to embody the coexistence of Chinese and Western medicine: 'There is a shelf for Chinese medicine on the east of the building, and there is another for Western medicine on the west. There are one table and a few benches in the middle. Between the two hangs a portrait of Chairman Mao and two newspapers.' This layout symbolises the unifying force. ${ }^{11}$

Meanwhile, the political circumstances of early 1957 are perhaps what prompted varying portrayals of the solutions to the tensions between Chinese and Western medicine and of the arrogance and bureaucracy of officials, along with the different backgrounds of the authors and the literary magazines they published in. 'Mr Li Si' was published in an official literature magazine - People's Literature - and so its depiction of conflict is relatively mild. In contrast, 'Medical Practice Incident' was published in the nonofficial literary magazine Spark, which is far more critical of bureaucracy as it claims that 'Spark

\footnotetext{
9 Xi Rong, 'Xingyi shijian' [Medical Practice Incident], Huohua [Twilight], 7 (1957), 17.

${ }^{10} \mathrm{Ibid} ., 21$.

${ }^{11} \mathrm{Li}$, op. cit. (note 8), 99-100.
} 
will be the spark that erupts from the life and struggles of the masses'. ${ }^{12}$ Hence, 'Medical Practice Incident' lambasts the government's support for the aggressiveness of Western medicine and the story does not end with a harmonious integration of Chinese and Western medicine - like that in ' $\mathrm{Mr} \mathrm{Li} \mathrm{Si'}{ }^{13}$

The significance of these two short stories is that they laid the foundation for literary narratives about Chinese medicine at a time when Western medicine had not yet entered villages on a large scale. These narratives reflect anxiety and nervousness around the status of Chinese medicine and point to practitioners' desire to struggle for scientific legitimacy by integrating Chinese and Western medicines. The scale of this tension is reflected in the pace of the entry of Western medicine into villages and the expansion of national medical and health programmes. Literary portrayals of either fierce tension or harmonious integration are often two sides of the same coin. Harmonious integration temporarily emerged as a theme in literary works in late 1957 when Chinese intellectuals who had criticised the Communist Party, including writers, were severely attacked and purged during the Anti-Rightist Campaign. Criticism of the bureaucracy in literary narratives became politically incorrect at this point, including critiques of medicine and health. The tension between Chinese and Western medicine that had appeared in earlier literary works was replaced by political enthusiasm and dedication to the reconciliation of Chinese and Western medicine. Characters in films and literary works that appeared after 1957 and reflect this pattern include an old Chinese medicine doctor and a CCP member in 'The Village Doctor', the Miao herbal healer in 'Herbal Medicine Doctor' and disabled veteran Zhao in 'The Rural Doctor'. ${ }^{14}$

However, narratives of tension between Chinese and Western medicine gradually returned to the mainstream in literary works over the following two decades. This may be partly due to narratives of tension being more gripping than stories of harmonious integration, but it also reflects the start of the mass epidemic prevention campaigns in the late 1950s, such as the anti-schistosomiasis campaign, which posed a dilemma for the government and Chinese medicine practitioners. Providing modern Western medicine to vast rural areas as part of this nationwide health and epidemic programme would have been immensely costly for the government, who addressed the problem by combining Western medicine with local medical resources (i.e. Chinese medicine). ${ }^{15}$ However, Chinese medicine practitioners in rural areas perceived these events as a real challenge to their medical knowledge and practices.

The tensions between the two types of medicine emerged in the new narrative styles. The most representative work was Spring Comes to the Withered Tree; a play that was performed by the Shanghai People's Art Theatre in 1959 and was made into a film directed by Zheng Junli in 1961. It tells the story of the treatment of a latestage schistosomiasis patient during the anti-schistosomiasis campaign in the late 1950s. The patient is protagonist Fang Dongge's sweetheart. ${ }^{16}$ In both the stage and film versions, there is serious tension around the treatment of the schistosomiasis patient

\footnotetext{
12 Dong Guohe, Yuedu luantan: Ershi shiji zhongguo wenren de fenggu yu zuiqiu [Causal Review: Characters and Aspirations of Chinese Intellectuals in the Twentieth Century] (Taipei: Xiuwei zixun, 2011), 178-81.

${ }^{13} \mathrm{Xi}$, op. cit. (note 9), 21.

14 Wang Wenshi, 'Cunyi' [The Village Doctor], Renmin wenxue [People's Literature], 11 (1958), 39; He Congxian, 'Caoyao yisheng' [Herbal Healer], Shanhua [Mountain Flower], 4 (1959), 25-6; Li Shuhua, 'Xiangcun yisheng' [The Rural Doctor], Renmin wenxue [People's Literature], 7 (1959), 72.

${ }^{15}$ Gross, op. cit. (note 5), 81-2.

${ }^{16}$ Kumu fengchun [Spring Comes to the Withered Tree], directed by Zheng Junli, Shanghai Film Studio, 1961.
} 
using Western medicine (as represented by the sent-down doctors) and Chinese medicine (symbolised by the rural locations they travel to). The controversy focuses on the efficacy of Chinese medicine in epidemic prevention and treatment. At the anti-schistosomiasis station, Dr Liu Xiang, a favourite student of schistosomiasis expert Professor Gao, insists that the heroine's schistosomiasis has already reached the final, incurable stage. $\mathrm{He}$ vehemently rejects the efficacy of Chinese medicine, claiming, 'It's impossible for Chinese medicine to cure schistosomiasis patients. It's futile to try Chinese medicine.' He thus concentrates on scientific research using chemical drugs. In contrast, Luo, the director of the anti-schistosomiasis station, and other colleagues insist that 'we should depend on our own country's medicine' and are confident that they will find an answer in ancient Chinese medical classics and clinical records. ${ }^{17}$ The tension between Chinese and Western medicine further comes to exemplify the struggle between different political paths. As critics have argued, the play depicts the struggle between two positions, two viewpoints, two attitudes and two methods, ${ }^{18}$ in which the anti-schistosomiasis station director and the Chinese medicine doctor represent the state will and the supreme leader's instructions. ${ }^{19}$

Literary portrayals of such tensions were useful for the government because they endorsed the legitimacy of Chinese medicine, whose practitioners were expressing anxiety and uncertainty, and mobilised them to participate in medical and health campaigns. In Spring Comes to the Withered Tree, for example, Chinese materia medica effectively reduces the patient's ascites; thus pointing to the efficacy of Chinese medicine. The film's criticism of dependence on Western medicine also effectively justifies the government's inability to provide medical services in rural areas, thus distracting from the unfair allocation of medical resources between rural and urban areas. For instance, director Luo insists the team can make up for medical and personnel shortages by shortening the antinomy therapy from a twenty-day treatment to a three-day one for ordinary patients, and that by doing so the station could finish curing all patients in the county within two years. Even in literary narratives, however, Western medicine is still indispensable and crucial. In Spring Comes to the Withered Tree, the tension is solved through perfect integration: the patient's ascites are reduced with Chinese medicine and the parasites removed by modern medical surgery.

By the mid-1960s, the tension between Chinese and Western medicine in literary narratives was further dichotomised and stereotyped. Local Chinese medical practitioners were portrayed as being committed to verifying the efficacy of Chinese medicine while integrating Chinese and Western medicine. Western medicine was criticised not for its claims of scientific legitimacy and efficacy, but for its suspicion of Chinese medicine. Though they reflect different political routes and attitudes, these conflicts are still relatively mild and are solved peacefully through the integration of the two approaches. A good example of this is the short story 'Medical Ethics' from 1961, which centres on an elite urban pediatrician, Dr Rong, and portrays Western and Chinese medicines as being perfectly complementary. ${ }^{20}$ This narrative style basically continued until the outbreak of the Cultural Revolution in 1966.

${ }^{17}$ Wang Lian, Kumu fengchun [Spring Comes to the Withered Tree], Shanghai xiju [Shanghai Drama], 3 (1959), $51-2$.

${ }^{18}$ Zhu Qing, 'Chunfeng yangliu wan qiantiao' [Millions of Spring Willows in the Wind], Xijubao [Drama Newspaper], 1 (1960), 10.

${ }^{19}$ Liang Dongfang, 'Kumufengchun: Ruhe jiejiu bingtong zhiku' [Spring Comes to the Withered Tree: How to Relieve Pains Suffered from Illnesses], Bolan Qunshu [Bolan qunshu], 9 (2014), 126.

${ }^{20}$ Ba Bo, 'Yidao' [Medical Ethics], Renmin wenxue [People's Literature], 9 (1961), 45-52. 


\section{Barefoot Doctors: Heroism, Medical Legitimacy and Quackery}

The next major shift in portrayals of medical practitioners in film and literature began in 1968, when barefoot doctors emerged as the new village healers. The barefoot doctor programme was at the core of the restructuring of the rural medical community that had been dominated by local Chinese medical practitioners and healers up to this point. However, their numbers were dwindling and the gradual influx of Western medicine described above had been challenging their legitimacy for some time. Barefoot doctors effectively replaced these Chinese medical practitioners and healers and became the main defenders of Chinese medicine. ${ }^{21}$ Meanwhile, the government continued to face the thorny issue of how to fund the nationwide provision of modern medical services to vast rural areas. The anxiety of Chinese medicine practitioners and government deliberation around funding were further exacerbated by the gradual formation of barefoot doctors' healing styles, which gave villagers comparative medical experience and resulted in a preference for Western medicine in rural communities. These factors are reflected in narratives concerning the tensions between Chinese and Western medicine in barefoot doctor films such as Chunmiao (1975), Hongyu (1975) and Yanming hupan (By the Yanming Lake, 1975 ) and the novel Chunfeng yangliu (Spring wind and willow, 1972). ${ }^{22}$

In these works, the medical knowledge structure of barefoot doctors is portrayed as being the perfect integration of Chinese and Western medicine. For example, in Hongyu, the eponymous hero trains at a county hospital where Chinese and Western methods are integrated. An old man holding a bunch of herbal medicines lectures barefoot doctor students, a middle-aged doctor is shown teaching Hongyu how to use a microscope, and a female teacher demonstrates how to perform acupuncture treatments. The barefoot doctors adopt stethoscopes as their main diagnostic tool, but acupuncture and herbal medicine are also emphasised as being effective. Chinese medicine (herbs and acupuncture) is portrayed as being politically and scientifically legitimate, while Western medicine (the stethoscope) is also indispensable for barefoot doctors.

A significant aspect of these films and novels is that although barefoot doctors are portrayed as the main defenders and practitioners of Chinese medicine, they are also shown to suffer fierce attacks from the medical practitioners and folk healers who dominated the rural medical community before their arrival. Another common theme is the criticism or delegitimisation of certain characters on both political and medical grounds. Characters such as commune clinic leader Qian Jiren in Chunmiao, Tao Chengjun in Spring Wind and Willow, Lin Daquan in By the Yangming Lake and Sun Tianfu in Hongyu are labelled class enemies because of their family origins and political labels. In Chunmiao, the heroine returns to her village and sets up a village clinic after studying medicine at the commune clinic, and she treats fellow villagers with herbal medicine collected from the mountains. However, the commune clinic leader looks down on these healing methods, arguing 'Did anyone use grasses and sticks to treat illnesses in the past?' Similarly, the

\footnotetext{
${ }^{21}$ Chunjuan Nancy Wei, 'Barefoot Doctors: The Legacy of Chairman Mao's healthcare', in Chunjuan Nancy Wei and Darryl E. Brock (eds), Mr. Science and Chairman Mao's Cultural Revolution: Science and Technology in Modern China (Lanham: Lexington Books, 2013), 253-5.

22 Chunmiao [Chunmiao], directed by Xie Jin, Shanghai Film Studio, 1975; Yang Xiao, Hongyu [Hongyu] (Beijing: Renmin wenxue chubanshe, 1973); Hongyu [Hongyu], directed by Cui Wei, Beijing Film Studio, 1975; Ji Yanhua, Yanming hupan [By the Yanming Lake] (Changchun: Jilin renmin chubanshe, 1973), 94; Yanming hupan [By the Yanming Lake], directed by Gao Tianhong, Changchun Film Studio, 1975; Sha Qun, Chunfeng yangliu [Spring wind and willow] (Shanghai: Shanghai renmin chubanshe, 1972).
} 
Chinese medical practitioner Sun Tianfu openly sneers at the barefoot doctor Hongyu for daring to administer acupuncture: 'I, Sun Tianfu, have been practicing medicine for thirty years. I have never dared to administer acupuncture. But Hongyu, a little guy, dares to do so.' 23

The growing doubt and mistrust toward Chinese herbal medicine and acupuncture that peasants were beginning to express were explained in these works as having been instigated by class enemies such as the characters described above. In By the Yanming Lake, villager Qian initially does not even know the names of Western medical treatments, but Lin Daquan incites him to ask for specific medications such as Terramycin and Tetracycline, claiming they are more effective than Chinese herbal medicine, in the hope that the cost of providing these will make the medical station go bankrupt. Qian takes the bait and throws away his Chinese herbal medicine. ${ }^{24}$ Similarly, in Spring Wind and Willow, the villagers refuse to take Chinese herbal medicine in the form of a heat stroke prevention soup prepared by the Barefoot Doctor Hongmei on the instigation of Doctor Tao Chengjun. ${ }^{25}$

While these films and novels justify the efficacy of Chinese herbal medicine and acupuncture in revolutionary discourse, they also highlight the source of treatment for chronic and serious illness in rural areas. In the films mentioned above, these include uncle Shuichang's serious waist and backache in Chunmiao, the old stonemason's poisoning in Hongyu, the old peasant Agen's late-stage schistosomiasis in Spring Wind and Willow and Granny Song's asthma in By the Yanming Lake. Each of these works draws attention to the orthodoxy and authority of the sources of Chinese medical treatment. For example, in Chunmiao and Hongyu, the recipes of two protagonists are from an old Chinese medicine doctor and an herbal medicine healer who lives high in the mountains. These herbal medicines are described as being immensely difficult to obtain as they are only found in remote locations, so the protagonists' have to exhibit great determination and courage to overcome the difficulties in collecting them. For example, the crucial herbal medicine for processing the pills for the old stonemason in Hongyu has to be collected from the top of a mountain because Chinese medicine claims that the higher the mountain, the better the quality of the medicine. Hongyu is portrayed as travelling over land and water, climbing high mountains, crossing ridges and even risking his life to collect medicinal herbs. ${ }^{26}$ In this narrative style, the rarity of these herbal medicines and the heroism that barefoot doctors demonstrated in collecting them all highlighted the legitimacy of Chinese medicine.

In these works, the barefoot doctors go even further, risking their lives to test the herbal medicines they went to such lengths to collect. A direct line is also traced between the reactionary rule of the Nationalists and the degree of seriousness of the illnesses that old, poor and lower-middle peasants suffer. These then require higher dosages of medicine, which contain more toxins and pose more risk to patients. ${ }^{27}$ In order to test maximum dosages and the toxin limits that the human body can endure, both Hongmei and Chunmiao test the herbal medicine decoctions they prepare on themselves, in an

${ }^{23}$ Hongyu [Hongyu], directed by Cui Wei, Beijing Film Studio, 1975.

24 Yanming hupan, directed by Gao Tianhong, 1975.

25 Sha, op. cit. (note 22), 138.

${ }^{26}$ Hongyu [Hongyu], directed by Cui Wei, 1975.

${ }^{27}$ Zhu Yong, 'Jibing zai geming zhong de mingyun' [The Destiny of Diseases in Revolution], Shuwu [The Study], 6 (2006), 70-6. 
expression of selfless revolutionary spirit. ${ }^{28}$ Both hesitate when the dosages make them faint, but Hongmei is described as hearing Chairman Mao's rousing declaration that 'if we consider people's interests and take the infliction of the majority of people into consideration, we die for the people. It is worth it' ${ }^{29}$ Eventually, Hongmei and Chunmiao recover from unconsciousness. In this way, these works of fiction effectively deny or overlook doubts around the sources and safety of Chinese medicine and justify its scientific legitimacy and efficacy because the human body was exposed to maximum dosages and toxins.

Despite their exaltation of Chinese medicine, these films and books never call the efficacy of Western medicine into question. Instead, what they criticise is the dependence on Western medicine in nationwide medical and health programmes like the barefoot doctor campaign. In these works, Western medicine remains the first choice of barefoot doctors and plays a key role in many cases. For example, Hongyu and Chunmiao establish their medical authority among villagers by curing flu and pneumonia, supposedly with herbal medicine. However, Hongyu is shown to administer an injection to reduce the patient's temperature first, and it is only after this that he prescribes herbal medicine. Likewise, Chunmiao supplies Chinese herbal medicine just because her prescription for Western medicine, her first choice of treatment, is refused by the commune clinic on the grounds that she is not eligible to prescribe it.

In these fictional works, the tension between Chinese and Western medicine is mostly reflected in the way that Chinese medicine and its practitioners, notably barefoot doctors, go to radical and dramatic lengths to defend its scientific legitimacy and efficacy while expressing their eagerness to integrate it with Western medicine. In this way, these works symbolise the integration of Chinese and Western medicine, but ultimately privilege the role that Chinese medicine played in treatment and prevention. However, the portrayal of this tension and of harmonious integration as the solution, along with the privileged role given to Chinese medicine in literary works, contrasts with the actual status of Chinese medicine during the nationwide barefoot doctor programme. Chinese medicine was in fact being rapidly marginalised in rural areas, while the government struggled with the heavy economic burden of providing the modern medicine services desired by rural dwellers, which they were instructed to privilege through mandates such as 'in medicine and health, focus on rural areas'. ${ }^{30}$ As a result, these fictional portrayals of Chinese medicine not only defended its legitimacy at this crucial moment of the introduction of Western medicine into China, but also sought to lighten the government's economic load by justifying the use of Chinese medicine.

However, the grand ideological shift from class struggle to socialist modernisation that came with the end of the Cultural Revolution in 1976 was complicated by the apparently contradictory statuses of Chinese medicine within China itself and abroad. On the one hand, the role of Chinese medicine in public health programmes garnered international acclaim as a model of primary health care for developing countries. This was also the time that Chinese medicine began to become popular and even trendy as an alternative medicine

\footnotetext{
28 The spirit of selfless dedication to medical and health has been widely promoted among medical staff in China since 1949. See Christos Lynteris, The Spirit of Selflessness in Maoist China: Socialist Medicine and the New Man (Basingstoke: Palgrave Macmillan, 2013), 2-5.

${ }^{29}$ Sha, op. cit. (note 22), 17-18.

${ }^{30}$ Sanchun Xu and Danian Hu, 'Barefoot Doctors and the "Health Care Revolution" in Rural China: A Study Centered on Shandong Province', Endeavour, 41, 3 (2017), 136-45.
} 
abroad. On the other hand, the practice of Chinese medicine within China, particularly acupuncture and herbal medicine, was being seriously challenged by Western medicine. ${ }^{31}$ The government was relieved of its political commitment to delivering modern medical services to rural areas in the name of reform and efficiency, as indicated by the end of barefoot doctor programme in the early 1980s. The government no longer had a vested interested in defending the legitimacy of Chinese medicine so it was happy to allow literary works to expose the problems of Chinese medicine. ${ }^{32}$ This change was first reflected in post-Cultural Revolution novels that look back on the experiences of sent-down urban physicians in the countryside from the late 1950s onward. One representative work from this period is the novel The Legend of Ghost House, published in 1987, which depicts the story of a group of doctors at a county anti-schistosomiasis station during the Great Leap Forward campaign. ${ }^{33}$ Chinese medicine, which had been portrayed as very useful in curing late-stage schistosomiasis in literary narratives in the 1960s, did not appear in this novel whatsoever. Instead, antimony is described as being the only available and effective medication for treating schistosomiasis. ${ }^{34}$ The novel discusses the situation of Chinese medicine in major medical and health campaigns exclusively from the point of view of urban medical professionals.

Unlike city dwellers, residents of rural areas were not only at the receiving end of this medical service from the 1950s to the 1970s, but they also witnessed radically changing medical and health reforms in the 1980s and afterwards, including the government's retreat from its commitment to medicine and public health and unrestrained marketisation. ${ }^{35}$ Similarly, the medical reforms from the early 1980s onward led to the disintegration of the barefoot doctor group, while those who continued practising medicine felt resentful, as though they were a 'lost generation' to some extent. ${ }^{36}$ The evolving experience of rural residents and barefoot doctors in different eras was a source for new literary narratives on the relationship between Chinese and Western medicine. Barefoot doctors and villagers return to the agenda as protagonists of film and literature in the 1990s and early 2000s. Criticism through literature had become less important as a social engineering tool, while intellectuals were perceived to be less of a threat to the political status quo. Literature, authors, protagonists and the literary critics who wrote about them were relieved of the burden to adhere explicitly to current political concerns. ${ }^{37}$ In this sense, literature and film were now able to present more realistic portrayals and sharper criticisms of the tension between Chinese and Western medicine.

The most influential literary work about rural medicine and health from this mostrecent period is Fan Xiaoqing's Barefoot Doctor Wan Quanhe, published in 2007, which

${ }^{31}$ Qian Xinzhong, 'Zai quanguo weisheng juzhang huiyishang de xiaojie' [Speech at the National Meeting for Director of Health Bureaus], 2 April 1979, Fuyang City Archives, Zhejiang Province, vol. 74-4-40.

32 David Blumenthal and William Hsiao, 'Privatization and Its Discontents: The Evolving Chinese Health Care System', The New England Journal of Medicine, 353, 11 (September 2005), 1165-70.

${ }^{33} \mathrm{Mu}$ Fu, Guiwu chunqiu [The Legend of Ghost House] (Guangzhou: Huacheng chubanshe, 1987).

${ }^{34}$ Ibid., 183. Regarding Chinese herbal medicine and medical practitioners in treating schistosomiasis, see Gross, op. cit. (note 5), 72, 153 .

${ }^{35}$ Ling Li, Qiulin Chen and Dillon Powers, 'Chinese Healthcare Reform: A Shift toward Social Development', Modern China, 38, 6 (November 2012), 630-45; Jane Duckett, The Chinese State's Retreat from Health: Policy and the Politics of Retrenchment (Abingdon, Oxon: Routledge, 2010).

36 Jiong Tu, 'The Lost Generation: "Barefoot Doctors" in Post-Reform China', China Perspective, 4 (2016), $7-17$.

${ }^{37}$ Louise Edwards, 'Women Sex-Spies: Chastity, National Dignity, Legitimate Government and Ding Ling's "When I was in Xia Village", The China Quarterly, 212 (December 2012), 1073-4. 
recounts the story of the eponymous protagonist from the late 1960s to the early twentyfirst century. ${ }^{38}$ Though the author provides a much more nuanced portrayal of the rural health scene in China than previous works, there are no particular references to the broader political context, such as the Cultural Revolution and the sending down of educated youth. Nor does the author portray major medical and health campaigns. Instead, her focus is entirely on a small community and how broader policies play out against this. As literary critic Wang Zheng points out, this perspective means that the novel avoids over-interpretation and keeps a distance from explicit politics and ideology, and further presents an authentic picture of daily life. ${ }^{39}$ In this narrative style, the representation of barefoot doctors essentially signifies the end of the stereotyping used in earlier narrative styles, but the shift is also ideological as it ruptures the propaganda model. In turn, this lack of ideological constraint goes hand-in-hand with a literary shift as it allows for more a profound characterisation.

In the novel, the relationship between Chinese and Western medicine is essentially a clash between Wan Quanhe's father, a longstanding Chinese medicine healer, and Tu Sanjiang, who receives five years of modern medical training and is sent down to the medical station during the Cultural Revolution. The novel discloses the sensitive and helpless mentality and behaviour of Wan's father as a defender of Chinese medicine. Wan tries to demonstrate his dignity as a Chinese medical practitioner and always criticises $\mathrm{Tu}$ for being unable to read and understand complicated classics of Chinese medicine. Meanwhile, he also proves himself able to understand and apply Western medicine in daily practice, such as by administering injections, prescribing anti-inflammatory drugs and referring patients for X-rays. In contrast, Western medicine Doctor Tu never shows any interest in studying or prescribing Chinese medicine, and looks down upon Chinese medicine practitioners. As he exclaims in the novel, Chinese medical practitioners 'don't know the directions of the door of medical school. Quack doctors and vulgar bumpkins! How dare you talk about curing patients?' ${ }^{40}$

In essence, the tension between Chinese and Western medicine in the novel is a continuity of the literary narratives since the 1950s, that is, it defends Chinese medicine and seeks to integrate it with Western medicine. Unlike the political interpretations in previous narratives, the tension between the two styles of medicine became riddled with personal conflict, contempt and even mutual animosity between Chinese and Western medical doctors due to the changing role of the state and state messaging. The novel does not provide a perfect or harmonious solution to the conflict between the two medicines, either. Ironically, it was Western medicine doctor and rival Tu who rescues Wan's father when he loses consciousness after being physically attacked at a struggle meeting and is put into a coffin to be buried. He survives, but, as the novel describes, 'His whole body is paralyzed. He can't speak and just murmurs occasionally. Only his eyes are alive and could move [blink]. ${ }^{41}$ The saving of the Chinese medicine practitioner's life is of course a metaphor for the predicament of Chinese medicine, which is at risk of losing its scientific legitimacy and being terminated altogether. Indeed, the aggressiveness of

\footnotetext{
${ }^{38}$ Fan Xiaoqing, Chijiaoyisheng wan quanhe [The Barefoot Doctor Wan Quanhe] (Tianjin: Tianjin renmin chubanshe, 2007).

${ }^{39}$ Wang Zheng, '2007niandu mingjia tuijian zhongguo yuanchuang xiaoshuo 4yue tuijianbang' [A List of Original Fiction Recommended by Famous Critics in April 2007], Shanxi wenxue [Shanxi Literature], 4 (2007), 95.

${ }^{40}$ Fan, op. cit. (note 38), 15.

41 Ibid., 53-4.
} 
Western medicine makes it very difficult for Chinese medicine to prevail. The timing of this incident in the novel is interesting: it takes place around the outbreak of the Cultural Revolution when the rural medical community was about to experience radical change from which barefoot doctors would emerge as the new village healers, introducing Western medicine into the village on a large scale. ${ }^{42}$

The novel describes relations between Chinese and Western medicine as becoming more dramatic by the time the protagonist Wan Quanhe starts to work as a barefoot doctor. Wan is supposed to study and continue to practise Chinese medicine under the mentorship of his father - as was traditional. Instead, what he studies and practises is Western medicine, although he sometimes consults his paralysed father, who communicates diagnoses by blinking. This blinking 'expert' is indicative of the last gasp of Chinese medicine. In this narrative, Western medicine has authority and is legitimate within the rural medical world. In contrast, the continuity of the pedigree of Chinese medicine is far from guaranteed, even when it is widely publicised through the barefoot doctor programme. It is further completely marginalised and relegated to being a cheap substitute for Western medicine in commercialised medical reform. Because of financial burdens, the medical station, jointly set up by Wan Quanhe and his staunch supporter, medical college graduate Ma Li, collapses. In order to reduce costs and solve the clinic's financial crisis, they start studying Chinese medicine classics, plant Fructus Corni and purchase some materia medica and process them into pills, which they test on themselves.

As mentioned earlier, the low cost of Chinese herbal medicine and the courage of barefoot doctors in testing dosages and toxicity on their own bodies are used to defend the legitimacy of Chinese medicine in literary narratives in the 1970s. However, these same circumstances are described in a very different light in Barefoot Doctor Wan Quanhe. After their experiment, both Wan and Ma realise that Chinese herbal medicine is not as effective as Western medicine. Ma even frankly admits to a patient: 'The efficacy of Western medicine is much better than that of Chinese medicine. ${ }^{43}$ Indeed, its side effects may be serious: Ma Li suffers severe flatulence after testing the medicine. Testing medicine on one's own body was supposedly highly valued in the political ideology of the Cultural Revolution, as it indicated dedication to rural medicine and healthcare. However, in the novel, the pharmaceutical agency rules that it is illegal to produce such herbal remedies and fines the clinic a huge sum of money, which almost causes it to go bankrupt.

Ironically, though Chinese medicine loses its scientific and political legitimacy, it becomes the reluctant last resort of those suffering from chronic illnesses, which results in a crazy pursuit for profit in the highly commercialised medical market. The book's final jibe at Chinese medicine revolves around the Wan family's secret recipe from the Chinese medicine classic The Inner Cannon of the Emperor Yellow, which is believed to cure hepatitis. One woman even actively courts Wan and cohabits with him in order to steal this secret recipe. When she and her real husband then start producing their own 'Panacea Syrup for Hepatitis', they cut a deal with hospitals and make a great deal of money from it. However, the remedy turns out to be made of cheap Isatidis Radix, honeysuckle and water from ditches, so patients eventually worsen after taking it. In the end, Chinese medicine is completely stigmatised and made synonymous with quackery in Barefoot Doctor Wan

${ }^{42}$ Fang, op. cit. (note 2), 33-41.

${ }^{43}$ Fan, op. cit. (note 38), 207. 
Quanhe. ${ }^{44}$ This novel thus fully engages with the dilemma at the core of the delivery of modern medical services to rural areas in the new political and medical contexts of the twenty-first century. The cost of Western medicine, which is interpreted as modern medicine, becomes increasingly unaffordable, but Chinese medicine is ultimately rejected. In this sense, the tensions between Chinese and Western medicine are actually fading from contemporary literary narratives as the former has been written out of the narrative as it is incapable of truly competing.

\section{Paraprofessional and Professionally Trained Doctors: Conflicts over Institutionalisation, Division and Hierarchy}

Along with Western medicine, professionally trained doctors were another crucial aspect of the delivery of medical services to rural areas in China. The experimental public health programmes in the 1930s selected and trained young villagers to work as health care workers, and assigned them strict duties related to vaccination, well-digging and the use of medical kits. ${ }^{45}$ This policy design and transient practice not only relieved the programme of the huge economic burden of providing professionally trained doctors, but also avoided potential conflicts between these outsiders and local medical communities in rural areas. ${ }^{46}$ Unlike its predecessor, the Communist government adopted a completely different approach after 1949 - the mobilisation and training of a large number of paraprofessionals in rural areas, which suffered serious scarcity and unfair distribution of medical resources. ${ }^{47}$ This practice resulted in another unresolvable tension between paraprofessionals and professionally trained doctors. This tension manifested in terms of the institutionalisation of administrative operations (such as venues, timetables and procedures associated with clinic consultations, etc.), the division of medical expertise, the identity of medical professionals and the hierarchy of professional proficiency (including the ways of knowledge transmission and doctor-patient relationships) - themes that are also reflected in fictional works from 1949 to the present.

Before the advent of Western medicine - conceived of as modern medicine - in the 1950s, medical culture in rural Chinese communities had its own logic. Medical knowledge, techniques and recipes were basically disseminated as hereditary family traditions. Anyone who had a certain amount of medical expertise could be regarded as a doctor. However, in reality, they were paraprofessionals at best. Nor was there any clear perception of professional medical identities. ${ }^{48}$ As the authors of ' $\mathrm{Mr} \mathrm{Li} \mathrm{Si'}$ ' and

\footnotetext{
44 The Nobel Laureate in literature, Mo Yan, published a novel entitled Wa [Frog] in 2009, which describes the history and development of obstetrics and gynaecology in rural China after 1949. In the novel, the main character expresses her contempt: 'What is Chinese medicine? All Chinese medicine practitioners are just half fortune tellers.' See Mo, Wa, 40. In the novel Dingzhuang meng [Dream of Ding Village], late-stage AIDS patients take herbal medicine decoctions that they don't think would extend their lives. They expect the new miracle medicine to fail and die in desperation. See Yan Lianke, Dingzhuang meng [Dream of Ding Village] (Hong Kong: Wenhua yishu chubanshe, 2005).

${ }^{45}$ Liping Bu, Public Health and the Modernization of China, 1910-2015 (London and New York, NY: Routledge, 2017).

46 C.C. Chen, Medicine in Rural China: A Personal Account (Berkeley: University of California Press, 1989), 83.

${ }^{47}$ Gross, op. cit. (note 5), 225; Hu Yi, Songyi xiaxiang: Xiandai zhongguo de jibing zhengzhi [Sending Medicine Down to the Countryside: The Politics of Diseases in Modern China] (Beijing: Shehui kexue wenxian chubanshe, 2011).

${ }^{48} \mathrm{Li}$ Ting'an, Zhongguo xiangcun weisheng wenti [Chinese Rural Health Issues] (Shanghai: Shangwu yinshuguan, 1935), 108.
} 
'Medical Practice Incident' suggest, practitioners obtain medical knowledge and recipes from families or through experience. In the two stories, Li and Niu are not full-time medical professionals because they spend a lot of time labouring in the fields or herding sheep. Treatment is given in the context of home-based medical encounters within the rural community. Patients and healers are in relatively equal positions, which breed mutual trust and respect. Nor is treatment an economic transaction. For example, in 'Medical Practice Incident', Niu never charges his patients money. Instead, as Niu recounts, 'after the treatment, families let their children call me godfather, or give me some gifts during Chinese New Year and festivals [to express their gratitude]. ${ }^{49}$ These traditional medical practices are not institutionalised in terms of venues, doctor-patient relationships and service rates. These two short stories vividly describe the medical practices of local medical practitioners before the advent of Western medical doctors and the establishment of union clinics in rural areas.

However, in 'Medical Practice Incident', this informality results in clashes within township clinics run by professional Western medical doctors, who accuse Mr Niu of prohibiting the masses from visiting the clinic. The health bureau director criticises him for taking gifts from fellow villagers, which he labels as exploitation. ${ }^{50}$ The two types of medical practitioners could not work alongside one another at an institutionalised clinic. In 'Mr Li Si', the protagonist clashes with a young Western medicine doctor over the clinic opening times: his young colleague posts one timetable on the door, but $\mathrm{Mr} \mathrm{Li} \mathrm{Si}$ puts up another, 'still following the old habit', which says that 'regardless of whether I am on duty or not, first come first served, even on rainy and windy days'. ${ }^{11}$ The two novels all set these conflicts in the context of the newly created union clinics in the mid1950s, which were mainly run by Chinese medical practitioners and folk healers like $\mathrm{Mr} \mathrm{Li}$ and $\mathrm{Mr}$ Niu, to address the scarcity of medical personnel. As mentioned earlier, Western medicine practitioners were then intentionally sent to these new medical spaces.

As literary narratives on Chinese medicine, these short stories demonstrate resistance and defensiveness on the part of rural paraprofessional doctors and healers when faced with institutionalised medical practices brought by professionally trained doctors, usually outsiders. For example, Mr Niu defends his nonprofit medical practice as medical benevolence and neighbourliness. In his words, 'The people live in this world. Shouldn't we have human benevolence?' ${ }^{52}$ Meanwhile, the short story is less critical of the young Western medical professionals at the clinic, their treatment methods, and medical proficiency. Instead, it criticises the bureaucracy and arrogance of the township director Huang, who is portrayed as supporting the strict institutionalisation of administrative procedures, the division of medical expertise and the maintenance of the identity of medical professionals and the hierarchy of professional proficiency brought by these Western medical practitioners. Mr Li and Mr Niu are excluded by their new colleagues because of support from bureaucratic and arrogant officials. The villagers experience a completely new form of medical encounter in an institutionalised space which abolishes affection, equality and the easy-going relationship they are used to with local doctors. They further interpret the medical practice as looking down on patients. For example, villagers are angry when these young doctors simply tell their children to drink plenty of water to

\footnotetext{
${ }^{49} \mathrm{Xi}$, op. cit. (note 9), 20.

${ }^{50} \mathrm{Ibid} ., 17$.

${ }^{51} \mathrm{Li}$, op. cit. (note 8), 100.

$52 \mathrm{Xi}$, op. cit. (note 9), 20.
} 
cure a fever. They are furious that the township director firmly supports the clinic while prohibiting Mr Niu from treating a child who is dying of a critical illness. ${ }^{53}$

Like the tension between Chinese and Western medicine, the authors' portrayals of the solutions to the tensions between local medical practitioners and newly arrived modern medical professionals vary in these short stories. By the end of the story ' $\mathrm{Mr} \mathrm{Li} \mathrm{Si}$ ', and following mediation by the director of the agricultural co-operative, $\mathrm{Mr} \mathrm{Li}$ and his young colleagues take down their different timetables and solve the tensions that arose from the institutionalisation of medical practice. In contrast, at the end of 'Medical Practice Incident', the quarrel between the director Huang and villagers achieves nothing.

This tension between paraprofessionals and professionally trained doctors was replaced by harmony in three works published between 1958 and 1959, namely 'The Village Doctor', 'The Herbal Medicine Doctor' and 'The Rural Doctor'. ${ }^{4}$ This shift perhaps reflects changes in the political and medical circumstances that arose during the AntiRightist Campaign (1957-9), which was to purge the alleged 'rightist' intellectuals who had voiced criticism against the Communist Party in the Hundred Flowers Campaign (1956-7). For example, veteran Zhao in 'The Rural Doctor' sets up a clinic and invites two Chinese medical practitioners labouring in the fields to join the clinic, in line with the Party's instructions. The three doctors get along well together. By the late $1950 \mathrm{~s}$, authors of short stories began to present narrative styles involving either serious tensions or harmonious integration between local paraprofessionals and modern medical professionals. In the texts, not only do local medical practitioners and healers defend themselves, they also prove willing to cooperate with other colleagues. In essence, these are responses to the impact of modern medical professionals, whose actions are interpreted in a political light, such as their service attitude to the masses. This narrative logic persisted in subsequent literary works.

As mentioned above, with the initiation of the mass epidemic prevention campaigns in the late 1950s, the entire dependence on the delivery of modern medical service by elite medical professionals became an economic challenge for the government. Negative fictional portrayals of these professionally trained doctors justified the governmental preference for low-cost prevention methods. This narrative is fully reflected in clashes over snail eradication in the stage and film versions of Spring Comes to the Withered Tree in 1959 and 1961, in which the attitude toward prevention is simplified as a dichotomy between two types of doctors following the camps of Chinese and Western medicine. The paraprofessionals in question include the director of the anti-schistosomiasis station, Luo Shunde, and his supporters include the protagonist, tractor driver Fang Dongge. The professionally trained practitioners in this case are sent-down urban doctors: Liu Xiang and his supervising professor, Professor Gao, a prestigious schistosomiasis expert. However, the latter does not show up personally. Dr Liu insists that anti-schistosomiasis work should prioritise eradicating snails entirely using chemical drugs, and highlights that 'this is what Professor Gao says'. In contrast, director Luo adopts active prevention strategies and measures, such as burying snails in soil using a tractor, which requires mass mobilisation. But, in Dr Liu's view, these are little more than crowd-pleasing strategies that are a waste of labour power and money. ${ }^{55}$

\footnotetext{
${ }^{53}$ See also Edward Friedman, Paul G. Pickowicz, Mark Selden with Kay Ann Johnson, Chinese Village, Socialist State (New Haven, CT: Yale University Press, 1991), 207-8.

${ }^{54}$ Wang, op. cit. (note 14), 39; He, op. cit. (note 14), 25-6; Li, op. cit. (note 14), 72.

55 Wang, op. cit. (note 17), 35, 43.
} 
In the play and the film, Dr Liu and director Luo represent the expert and mass routes of extermination respectively; the latter was the politically correct option at the time of production. As one critic pointed out: 'Only in this way can we control, reduce, and eradicate the plague within the shortest time. ${ }^{56}$ Director Luo represents politically loyal and reliable paraprofessionals, while Dr Liu is a bourgeois intellectual and elite medical professional. As another film critic observed, Liu never seems to care about the lives and deaths of the masses. His only aim is for his own experiment to succeed and for him to become famous. ${ }^{57}$ Therefore, the tension between Liu and Luo is interpreted as the conflict between proletariat solidarity and bourgeois individualism, which symbolised the confrontation between the two opposing schools of thought with their different pursuits and methods. ${ }^{58}$ Like the tension between Chinese and Western medicine, the tension between the two types of doctors ended peacefully through cooperation. In the narratives, Dr Liu is criticised for his nonrecognition and support of paraprofessionals and the prevention route they represent, rather than his medical proficiency. At the same time, his expertise is appreciated as the Party depends on him to operate on the late-stage schistosomiasis patient, who is described as a victim of the 'reactionary and decadent rulers'. 59

The tension between paraprofessionals and professionally trained doctors in literary works concerning barefoot doctors after 1968 basically followed the same theme that had emerged since the mid-1950s. As 'Newly Emerged Things' of the Cultural Revolution, the barefoot doctor programme was an attempt to further blur the boundaries between paraprofessionals and professionally trained doctors, even though the barefoot doctors did receive some short-term medical training. While undertaking epidemic prevention and public health duties with health workers, barefoot doctors assumed the role of physicians and treatment became an important part of their daily work. In the movies and novels concerning barefoot doctors, the main characters Chunmiao, Haiying and Hongmei all set up medical stations or clinics and even surgery rooms.

However, as indicated earlier, the rise of barefoot doctors is depicted as seriously challenging the structure of the rural medical community, which, by that point, was dominated by professional medical doctors. The medical businesses and authority of these medical professionals seriously suffered with the emergence of barefoot doctors, and the already divided community was fractured yet again by the arrival of another group of professionals: sent-down urban doctors, including the middle-aged surgeon Dr Pan in Spring Wind and Willow, the young surgeon Lan Haitao in By the Yanming Lake, the new medical graduate Fang Ming in the film Chunmiao and Dr Sang at the county hospital in Hongyu. These elite medical physicians needed to downgrade their professionalism or deprofessionalise their activities to blur the boundaries between them and paraprofessionals. Under the new professional divisions, they were required not only to play a role in public health and epidemic prevention, but also to adopt low-cost methods that were of a lower quality than they were used to. ${ }^{60}$

56 Zhu, op. cit. (note 18), 10.

57 Ibid.

${ }^{58}$ Li Chao, 'Ping kumu fengchun de yanchu' [Comments on the Performance of Spring Comes to the Withered Tree], Xijubao [Drama Newspaper], 3 (1960), 22.

${ }^{59} \mathrm{Zhu}$, op. cit. (note 18), 9.

${ }^{60}$ Zhang Xun, 'Wuchan jieji wenhua dageming de zange: ping caise gushipian chunmiao' [The Paean of the Great Proletariat Cultural Revolution: Comments on the Colour Movie Chunmiao], Zhejiang Ribao [Zhejiang Daily], 2 December 1975. 
In this narrative style, even though both rural and urban medical professionals are professional medical practitioners, they are defined differently. The tension between barefoot doctors and established rural medical practitioners transitions into a political dichotomy cantering on who controls medical power, whose interests medicine and health work should serve, and how these tasks should be undertaken. These rural medical doctors are portrayed as prohibiting young poor and lower-middle peasants from studying medicine in order to continue to wield medical power in rural communities through coercion, temptation and sabotage. In the film Chunmiao, commune clinic director Du orders Chunmiao to close the clinic and stop providing medicine for it on the grounds that 'medicine is science. To administer injection needles is completely different from holding hoes ... Hands that hold hoes cannot shape ceramics.' Meanwhile, in contrast with the barefoot doctors' warm-hearted service and dedication to poor and lower-middle peasants, the medical team leader Qian is keen on expensive scientific research into medications that would help prolong government officials' lives and improve their general health, rather than treating peasants with specific ailments. Though both Sun and Tao treat villagers, they prescribe expensive materia medica and antibiotics for common illnesses in order to make money. These fictional works actually address two crucial factors in any nationwide health programme: providers and the cost of medical service. The criticism levelled against these rural medical practitioners justified the utilisation of readily available barefoot doctors as paraprofessionals, which sought to blur the divide between them and medical professionals. The cost of medical research and these medical professionals' allegedly fraudulent manipulation of limited medical resources justified the low-cost medical service provided by paraprofessionals.

The portrayals of sent-down urban doctors are not the main target of criticism in literary works. Instead, their portrayals are much more nuanced than those of rural medical practitioners. They carry little political stigma due to their family origins and political labels - indeed, some of them even have glorious revolutionary backgrounds. For example, Dr Lan Haitao, in By the Yanming Lake, is the son of a Communist martyr. The problem for sent-down doctors is their wavering political stance regarding the revolutionary health route represented by barefoot doctors, such as unwillingness to serve in the countryside. For instance, Dr Lan is very worried. As he explained: 'There are no basic surgery facilities in the village medical station. I can't apply my medical expertise in the work here. At long last, I won't be able to fulfil my career dream. ${ }^{61}$ However, in these fictional portrayals, they are politically re-educatable. They strengthen their political consciousness 'under the guidance of the correct route supplemented by the re-education of workers, peasants, and soldiers' ${ }^{62}$ Meanwhile, their medical expertise is indispensable for barefoot doctors, who they instruct on medical matters while providing guidance in major surgeries. More significantly, they are shown to readily de-professionalise themselves, such as by adapting to the new professional divisions with barefoot doctors, actively conducting public health and epidemic prevention work, and adopting low-cost folk methods.

Joining forces with these sent-down urban medical professionals, barefoot doctors successfully thwart the attacks and plots launched by the established professional doctors who dominated the rural medical community, such as Sun Tianfu's attempt to murder

$61 \mathrm{Ji}$, op. cit. (note 22), 200.

62 "Cong "chijiao yisheng" de chengzhang kan yixue jiaoyu geming de fangxiang: shanghaishi de diaocha baogao' [Fostering a Revolution in Medical Education through the Growth of the Barefoot Doctors: An Investigative Report from Shanghai Municipality], Renmin ribao [People's Daily], 14 September 1968. 
Hongyu. In this way, films and novels offer a solution to the tensions between barefoot doctors and the two types of medical professionals. More significantly, literary works perfectly blur the boundaries between barefoot doctors and professionally trained doctors. As a critic writes about the movie Chunmiao, compared with medical physicians who 'received professional training', the only difference between the two groups is that barefoot doctors did not attend formal medical colleges - the implication is thus that medical proficiency is not necessarily related to medical college education, which should not be blindly trusted, as college is not where authentic proficiency is obtained. ${ }^{63}$ Barefoot doctors therefore present a glorious embodiment of the new type of paraprofessional socialist doctors in rural China. ${ }^{64}$

However, these sorts of interpretations of and solutions to the tensions between the two types of doctors were soon discarded and even reversed with the end of the Cultural Revolution and the rise of the medical modernisation discourse. On the one hand, the professionalisation of paraprofessionals lost its legitimacy when the State Council announced the end of the barefoot doctor programme, which then disintegrated. ${ }^{65}$ The de-professionalisation of formally trained medical professionals also suffered criticism, particularly those sent down to rural areas. As Minister of Health Qian Xinzhong said of this practice in 1979: 'Mobilisation work was too simple in some areas ... We did not take the practical situations of sent-down medical staff seriously. Some were sent down by coercive force, while others who were old, fragile, and ill were also sent down. ${ }^{66}$ In fictional works from this time, such as Chen Rong's novel At Middle Age and Sang Hu's slightly earlier film Song of Acupuncture Treatment, ${ }^{67}$ professionally trained doctors started recounting the persecution they suffered during the Cultural Revolution and expressed their dedication to medical work and scientific research as part of the socialist modernisation project. Mu Fu's novel The Legend of Ghost House is basically a narration of the bitter sufferings of sent-down urban doctors, which completely overturned the narratives on the integration of two types of doctors in the anti-schistosomiasis campaigns portrayed in both versions of Spring Comes to the Withered Tree.

Similarly, socio-political changes relieved practitioners of government ideological obligations and the need to blur boundaries between paraprofessionals and medical professionals that had characterised the previous decade. As mentioned earlier, those who stayed on to practice medicine in villages also began to experience the impact of marketdriven medical reform. The continuous experience of both barefoot doctors and villagers became a source for literary works on medicine and health in rural areas. For example, the novel Barefoot Doctor Wan Quanhe, published in 2007, portrays the tensions between the protagonist Wan Quanhe and modern medical professionals within two different sociopolitical and medical contexts that emerged after the late 1960s.

Unlike literary portrayals of the Cultural Revolution, the internal rural medical world is not described as undergoing radical reshuffling and classification in this novel.

\footnotetext{
${ }^{63}$ Miao Yu, 'Fanji weisheng zhanxian youqin fan'anfeng' [Repulse the Right-Deviationist Wind to Reverse the Verdict on Health Front], Zhejiang Ribao [Zhejiang Daily], 3 April 1976.

${ }^{64}$ Hepuxian renmin yiyuan pinglun xiaozu [Commentary team of Hepu County People's Hospital], 'Xikan chunmiao zhuozhuang chengzhang' [Happy to See Spring Sprouts Grow Rigorously], Guangxi weisheng [Guangxi Health], June (1975), 16.

65 Fang, op. cit. (note 2), 166-76.

${ }^{66}$ Qian, op. cit. (note 31), 2 April 1979.

${ }^{67}$ Chen Rong, Rendao zhongnian [At Middle Age] (Tianjin: Baihua wenyi chubanshe, 1981); Wuying dengxia song yinzhen [Song of Acupuncture Treatment], directed by Sang Hu, Shanghai Film Studio, 1974.
} 
This narrative style shows the significant and incisive ways in which the past can be memorialised and reconfigured. Although Wan's father, a traditional medical practitioner, is criticised at the 'struggle meeting against class enemies', the medical community basically remains intact, resting on its pedigree and knowledge-transmission structure. The way that Wan Quanhe becomes a barefoot doctor is dramatic and largely accidental. Being born into a family known for a folk medicine recipe, Wan becomes a barefoot doctor by chance just because he successfully removes a bean from the ear of a little boy. Unlike those glorified barefoot doctors who scaled high mountains to collect herbs for medicine and operated on patients, Wan's medical proficiency is so limited that he initially does not even dare to give his patients injections. As a paraprofessional, he does not obtain strong support from traditional practitioners and folk healers who are supposed to help him. The other doctors at the village clinic, including his father and even the folk healer $\mathrm{Hu}$, all sneer at his lack of expertise and general stupidity. Wan himself is so lacking in confidence that he repeatedly tries to resign from the clinic. Yet at the same time, Wan is portrayed as a caring and responsible person who even goes so far as to suck the phlegm from the throat of an asthma patient. As a character, he is much more contradictory and multifaceted than barefoot doctors in earlier fictional works.

More significantly, in these later works, paraprofessionals like Wan Quanhe are described as being unable to actively clash with professionally trained doctors within the hierarchy of the medical system. Instead, Wan is embarrassed, disadvantaged and frustrated with his relationships with three types of professionally trained doctors during the Cultural Revolution, the economic reform era of the 1980s and the medical marketisation era that began in the late 1990s. In the novel, Dr Tu is sent down to the village twice during the Cultural Revolution. As a medical professional with five years of medical training, Tu is ashamed of working with barefoot doctors at the village medical station. His identity as a professional who is part of the medical hierarchy endows him with a sense of superiority and he looks down on Wan, his apprentice, for his poor medical proficiency, saying: 'I firmly believe that you are an idiot.' ${ }^{68} \mathrm{He}$ repeatedly requests to leave the countryside and finally succeeds.

Dr Tu's reluctance and eventual return to the city indicate the end of the delivery of modern medicine by formally trained medical professionals in rural China in the Mao era. Barefoot Doctor Wan Quanhe portrays another urban medical professional, Ma Li, who arrives when Wan Quanhe alone is left practising medicine at the village clinic. Unlike Dr Tu during the Cultural Revolution, Ma Li has a close relationship with village life and goes to the countryside voluntarily. As the daughter of former sent-down cadres in the village, the young medical graduate returns to set up a union clinic in partnership with Wan Quanhe. She is portrayed as being dedicated to the clinic and trying her best to reduce costs. Initially the book seems to be suggesting that there is active cooperation between paraprofessionals and modern medical practitioners in the countryside. However, Ma Li gradually realises that she is unable to fulfil her grand goal and is expecting too much of her barefoot doctor partner. At last, Ma leaves the village with a sense of disappointment and desperation. In Wan's own words: 'Ma Li realised that she made a serious blunder, which has wasted many years of her precious youth. She should not waste any more. ${ }^{69}$

In the novel, doctors $\mathrm{Tu}$ and Ma represent the two ways that professionally trained doctors can serve the countryside: compulsorily and voluntarily. The failure of both

${ }^{68}$ Fan, op. cit. (note 38), 83-5.

${ }^{69}$ Ibid., 213. 
these methods dwells on the dilemma of the delivery of modern medical services to the countryside, where urban medical professionals are either unwilling or unable to change rural medical and healthcare situations even working alongside barefoot doctors. The author of Barefoot Doctor Wan Quanhe recounts the retreat of the state and even urban medical professionals, who are sympathetic to the plight of the countryside (like Ma Li), from rural medicine and health. It also strengthens the notion of the professional hierarchy, notably in terms of the divide between rural and urban areas under the impact of medical marketisation. In this medical system, protagonist Wan Quanhe - the only one who stays in the village throughout each period - is relegated to a more disadvantaged position. As a conscientious and kind doctor with limited medical proficiency, he always accompanies his patients to visit professional doctors at commune clinics and urban comprehensive hospitals. However, when he does so, he is humiliated and criticised by the third type of professionally trained doctor. In the case of a chronic hepatitis patient, an urban doctor yells at Wan for delaying treatment and criticises him, saying 'you're not qualified to work as a doctor'. Similar mortification is endured by villagers; in the novel, an old villager is humiliated by a woman doctor at an urban hospital because he is unable to understand the doctor's instructions given in Mandarin, rather than his dialect.

The novel ends with Wan sitting next to his paralysed father and staring at the road connecting the village with the outside world. He laments: 'Everyone has left, leaving my father and me behind. It doesn't mean we don't want to leave. However, there is nowhere we can go. ${ }^{70}$ Wan's words vividly express the frustration of paraprofessionals in the face of changing medical contexts. Ironically, only at the end of the novel does the author disclose that the protagonist had meningitis at the age of three, which affected his brain. As the author argues: 'No one takes rural medicine and health seriously. No one cares about the treatment problems poor peasants face. Only Wan does. ${ }^{71}$ As one literary critic has remarked, the author intends to express her concern and anxiety over rural health and medicine from 'the perspective of a fool' ${ }^{72}$ In other words, she intentionally chose a fool as her main character to undertake the important duty of providing rural medical services in the radically marketised medical system, which she ultimately suggests is on a fool's errand.

\section{Conclusion}

Chinese medicine and paraprofessionals were mobilised after 1949 as readily available resources and easily trained personnel in rural communities. Films and literature from the 1950s to the 1970s idealised medicine and health scenarios in rural areas. Chinese medicine and acupuncture were also shown to be almost magical in their efficacy, while rural paraprofessionals such as barefoot doctors demonstrated great determination, enthusiasm and dedication to medicine and health work in these locations. As I have indicated in this article, despite the government's attempts to portray its medical services to rural areas as a success, the literary works under discussion showed that real problems continued to exist in rural health care during this time because of the unresolvable tension between the proficiency of Chinese and Western medicine. These narratives demonstrate

70 Ibid., 314.

${ }^{71}$ Fan Xiaoqin and Wang Zheng, 'Denghuo lanshanchu yu chijiao yisheng wan quanhe youguan he wuguan de duihua' [Relevant and Irrelevant Conversations about the Barefoot Doctor Wan Quanhe in the Lights], Xibu Ниауи wеnхие [Western China: Chinese literature], 5 (2007), 102-3.

72 Wang, op. cit. (note 39), 95. 
how the CCP addressed popular anxieties and expectations about health services and the interests they supposedly served. They show the fantasies and ideals that the CCP created and perpetuated, while studiously ignoring and refusing to examine some key issues relating to rural health. In this way, the narratives further justify the legitimacy of the Communist regime in the context of the unfair distribution of limited medical resources. Meanwhile, these fictional narrations also provide insight into the defensive stance that Chinese medicine and paraprofessionals had to take as they struggled against the impact and challenges that came with the establishment of the modern medical system and the restructuring of rural medical communities, including the advent of Western medicine and professionally trained doctors.

Relieved of ideological constraints and obligations when the marketisation of the healthcare system began in the late 1970s, the government retreated from rural medicine and health and demonstrated no interest in protecting the success of the old system. Different participants, such as sent-down medical physicians, local doctors, and villagers, have recounted their own experiences and sufferings in the decades since then, many of which have become sources for fictional accounts such as those I have discussed. The radical changes brought by the ongoing medical reform also contributed to these new fictional narratives that provide different perspectives on the ongoing tensions between Chinese and Western medicine and between paraprofessionals and professionally trained doctors from 1949 to the present. More than anything, the narratives have revealed the widespread anxiety and desperation that have underpinned rural medicine and health issues in contemporary China. The fictional works that I have discussed in this are significant because they provide insights into the reigning ideologies at the time of their publication or release and include nuanced descriptions of the crisis in the scientific legitimacy and efficacy of Chinese medicine and the clashes over institutionalisation, division and hierarchy within the medical system in rural China after 1949. 